\title{
The Study of Agricultural Intellectual Property and Intelligent Agriculture Development Strategies in China
}

\author{
Duanyang Ren, Wei Song, Zhangzhi Ge \\ School of Public Affairs, University of Science and Technology of China, Hefei, China \\ Email: rdy@mail.ustc.edu.cn
}

How to cite this paper: Ren, D.Y., Song, W. and Ge, Z.Z. (2017) The Study of Agricultural Intellectual Property and Intelligent Agriculture Development Strategies in China. Journal of Service Science and Management, 10, 230-250.

https://doi.org/10.4236/jssm.2017.103020

Received: May 25, 2017

Accepted: June 5, 2017

Published: June 8, 2017

Copyright (c) 2017 by authors and Scientific Research Publishing Inc. This work is licensed under the Creative Commons Attribution International License (CC BY 4.0).

http://creativecommons.org/licenses/by/4.0/

\begin{abstract}
Agriculture is the basic industry of our country, which plays an important role in the food security and social stability of China. As the implementation of China's strategy of innovation-driven development, the number of agricultural intellectual property application in China has been gradually increasing, the R \& D ability of agricultural research has been improved. However, the work of agricultural technology transform has been not going well, lots of agricultural patents have been put on hold, which can't create economic value and social benefits. Thus this paper explores that what affect the performance of technology transformation, and how allocate the resource reasonably to improve the benefits of technology transformation. We collected data from the statistics of universities' technology, using the agricultural technology data to examine the relationship between funding input, researchers, technology transfer service people and some other resources and the performance, such as paper, patent and economic benefits. This paper concludes that the researchers and technology transfer service people play an important role in technology transformation, and different research types also lead to different outputs, which could give guidance for resource allocation and making policy.
\end{abstract}

\section{Keywords}

Agricultural Intellectual Property, Intelligent Agriculture,

Advice and Suggestion

\section{Background}

Due to globalization and the coming of the Internet era, the refresh cycle of technologies is shortening, and the renewal and spread of knowledge is speeding up, which makes innovation become the most important driving force of today's society development, leading to fiercer competitions in the field of innovative 
intellectual property. Significant technological achievements are influencing the society's production and life, and innovation is deeply involved all over the world. Therefore, as a crucial output of innovative activities, intellectual property is involved in commercial operations in the market system, which generates relevant business and various operation platforms [1]. Many approaches such as transfer, reception of intellectual property and financing can combine the property and social development, therefore occupy the leading position of technology reform and industry development. As to agriculture, traditional methods have problems such as weak competitive power, low yield and climate limitation, and are challenged due to the appearance of new technologies including Internet of Things (IoT), transgenosis and plant-chip. As a result, technicalization and modernization will become the features of the new intelligent agriculture, and it will lay much more emphasis on science and technology. The range of agricultural intellectual property is quite wide, including new plant species, new patent, new brand, new confidential technology, geographic symbol, etc. Intellectual property can improve agriculture's competitiveness in the market. In our country, the input of agricultural innovation keeps increasing, however, the efficiency of achievement transfer does not match the expectation [2]. One of the reasons is that some agricultural universities and research institutes are not aware enough of the importance, and the features and special requirements in the industry, such as the production period, pilot test and the outcome test are another problem.

The government has realized the importance of technological innovation in agricultural development and published a series of policies and regulations. "Strategies outlines on National Intellectual Property", "Strategies outlines on Agricultural Intellectual Property (2010-2020)" and "Guidelines on improving the development of intellectual property service" all provided guidance for our country's agricultural intellectual property operation [3].

Besides, the leaders of our nation also offered many advices on the development of agriculture and technologies. Chairman Xi raised the concept to change the style of agriculture, including improving the industry ecosystem, upgrading the product structure, improving green agriculture service system, expanding scale of the industry, realizing dynamic transfer of agricultural development, structure transition and the industry's work methods. Chairman Xi also put great emphasis on technology improvement, indicating that this is the key to achieve finer management and promote industry upgrade therefore to establish more comprehensive industry system and realize modernization. During his investigation in Henan Province, Premier Li also stressed the significance of new technology and new thoughts in developing a way of combing the Internet with agriculture and reforming the industry's supply in order to improve farmers' life.

In 2016, with the lead of Agriculture Science Institute and cooperation of many universities and research institutes, National Intelligent Agriculture Science and Technology Innovation Alliance was established, meaning that there are laws and regulations to approve and support the development of intelligent agriculture [4]. The main target of this alliance is to coordinate resources and 
technical advantages in order to overcome difficulties in developing agricultural techniques and promote the application of them [5]. This would assist innovation to develop intelligent agriculture and therefore improve the whole industry.

In 2017, government's first priority document analyzed the current situation of the agricultural supply reform and provided guidance of the new developing method, which is to change the traditional production style, focus on green and organic and combine the agricultural technologies and development with the economy of the countryside. Furthermore, the operation and assessment of agricultural intellectual properties should also be further explored.

However, in our country, the transfer of technical achievements is at a rather low level and many patents are not being used because of the incomprehensive operating system of intellectual property and low awareness of scientists and researchers. There are such problems in the field of agricultural intellectual properties, for example, there is a shortage of qualified operating staff, the relevant system and regulations are not fully developed, and some theories cannot be applied to practice [6]. Besides, agricultural intellectual property is slightly different with other innovation outcomes in operation due to its features, and the long profit recovery period also results in lack of motivation to transfer the outcomes. Furthermore, traditional agricultural approaches is dominant in our country therefore it's even harder to apply new technologies on a large scale. In this report, a transfer system is established after considering the features of agricultural intellectual properties and current problems of the transfer process in order to better promote the development of intelligent agriculture.

This paper focuses on the path agricultural intellectual property operation and the way of affecting the development of intelligent agriculture. At first, we explore the affecting mechanism of agriculture intellectual property operation, and how distinguish which factors influence the performance of technology transformation. The analysis path of this research has two levels, first, using the comprehensive variables to predict the adjusted relationship between adjusted variables and dependent variables. Then applying the sub-variables to the model and analyze the factors which influenced the outputs of technology transformation, and compared with the results of comprehensive variables. Thus we can find the endogenous mechanism of agricultural intellectual property operation.

\section{The Necessity of Developing Agricultural Intellectual Property and Intelligent Agriculture}

\subsection{Developing Intelligent Agriculture by Technology Innovation Is an Important Guarantee of Assisting Technologically under Development Regions}

With the specified supporting-the-poor plan being carried out more thoroughly, helping farmers to increase their income and get rid of poverty is critical for our society's stable development. Instead of just fulfilling their material demands, we should offer them techniques and enable them to create what they need. To achieve this, technologies are relied on. Primary agricultural products should be 
further processed to create additional value. New species and technologies should be associated into the production, and make agriculture industry more elaborate and interactive by focusing on advanced and featured species, green and organic products and tourism in order to make up the disadvantages of current production methods and achieve informatization in agriculture.

On the other hand, self-motivated scientific innovation should be encouraged and up-to-date technologies should be popularized and applied into planting, breeding and by-product processing [7]. Leading brands and enterprises should be established and supported to achieve production of larger scale by using Internet platforms as well. Agricultural science parks should be built, where farmers can access education and improve their science knowledge and civilization, and technological outcomes can be transferred to remote and poor areas. Through the development of intelligent agriculture, the economy of surrounding areas can be improved and the farmers can get rid of poverty.

\subsection{Improving International Competitiveness of Our Country's Agricultural Products with "The Belt and Road" Strategy}

With the implementation of "The Belt and Road" (B \& R) strategy, our country has strengthened communication and cooperation with countries within the scheme, therefore expanded the market for agricultural product export and is also facing more intense competition. Since those foreign countries all have different dietary habits and culture, the exported products should be not only with higher quality but also cope with specific demands to expand potential markets. For example, some countries prefer black tea but the dominant product of our country is green tea, which becomes less competitive [8]. Meanwhile, high quality products from other countries are also imported into our market, which also leads to more pressure on the sale of our own products.

The B \& R strategy brings more opportunities and provides a positive environment to upgrade the industry structure and standard of agriculture. Under this circumstance, our country should keep concentrating on new technologies to improve the product quality in order to meet the international standards, and create more diversity and features to establish advanced agricultural brands. Besides, organizations such as the China-Africa communication department of Chinese Science and Research Institute, national agricultural technology transfer center and Chinese-Middle Asia technical cooperation center should work together to accelerate the technology innovation and interaction in related regions, and encourage the export of advanced products and technologies to improve their competitiveness [9]. China can form a combination with nations involved in the B \& R strategy and participate in the pricing and regulation setting in the international agricultural market.

\subsection{The Urgency of Advanced Agricultural Technology Development and the Interaction between Agriculture and Economy}

Traditional agricultural production has many disadvantages such as low addi- 
tional value and unstable product quality caused by the impact of environment and usage of pesticide, which makes the product fail to meet the standard of EU and Japan and be exported, leading to a great loss. Besides, the traditional production also releases a great amount of waste such as straw, husk and nutshell. The massive use of chemical pesticides and waste of water also deteriorate the eco-system and hinder the sustainable development [10]. These negative situations make the application of up-to-date technologies and intelligent agriculture an urgent demand. The establishment of comprehensive national scientific centers has started in Shanghai, Beijing and Hefei, and these centers will serve as the foundation and leading role of our country's innovation system. Current scheme shows that other disciplines such as material, environment, energy, physical, geology and medical are more focused on instead of agriculture, which illustrates that the transfer of technological outcomes in this field should be further developed to keep pace with other disciplines.

On the other hand, the application of Internet economy should also be strengthened to increase the capital flow into agriculture. Currently, the agricultural production in our country is mainly operated on a small scale and finds it difficult to get financing and update technologies and equipments on a large scale. The government is encouraging a new mode combing agriculture and economy online, which uses financial tools to create ways to apply for agricultural loan, mortgage and financing [11]. With assistance of the new mode and development of innovative agricultural technologies, agriculture and economy can be associated more closely, which can lead to high quality products, brands and economical derivatives and further develop agricultural industry.

\section{Case Study}

\subsection{Theoretical Foundation}

\section{Basis of Research}

The relationship between research input and achievement transfer and output is always a focus of worldwide study. The development of technologies can pose direct influences on the industry's structure upgrade and performance. Since the enterprises in the agricultural industry are still of small scale therefore the innovation input is low, and the profit recovery period is rather long, the main body of technological innovation and transfer is universities and research institutes. This is another way to demonstrate universities' social responsibility [12]. Recently, how to measure the transfer performance of the technological outcomes is also a fervent topic. It is realized that paying effort to research and innovation can not only result in academic outcomes such as papers and patents, but also bring economic and social benefits by transferring these outcomes.

Besides, some scholars believe that the linear relationship between the input and output of scientific research cannot be fully described if the input only includes financial cost and human resource. The influencing factors of technological outcome transfer should also be considered. Focusing on a single index can lead to neglect of the impacts caused by different types of resource input. There- 
fore, in this report, not only the impact of comprehensive variable but also that of every sub-variable is analyzed. A model of agricultural scientific research input is established and regulated variables are introduced to further evaluate whether the variables can have positive regulating effects, which provides a theoretical foundation for research resource allocation and technological outcome transfer of universities in our country.

\subsection{Index Selection}

Since this report studies the impacts on technological outcome caused by research input, the features of agricultural research and outcome transfer should be taken into consideration when selecting indexes. The agricultural technologies also work for the public welfare so the social benefits should be assessed other than just economic benefits when evaluating the transfer performance. The economic benefit is the main driving force of the transfer but the social benefit can promote the spread and deepening of technologies and knowledge, and serves for further innovation. Besides, as is mentioned before, not only the overall index but also the sub-indexes should be studied specifically.

Since the main body participating in the agricultural technological outcome transfer is universities and research institutes, the data used in this report is the data of agricultural and forestry universities' research input and output from 2000 to 2016, chosen from “Universities" Technological Statistics Collection' (which is referred to as the Collection below). It collects the output of universities of China, including agricultural industry, pharmaceutical industry, IT industry, et al. which reflecting the input and output of university's technology research. The published press is the National Bureau of Statistics. The human resource input, research funding input and technology transfer funding input of agriculture are chosen as independent variables, and the number of patent, published papers and real income created by technology transfer are the dependent variables. By considering real influencing factors of the transfer, the number of funding project, the cost of project research and human resource input of technology transfer service are viewed as three regulating variables to study their impacts. The following is detailed explanation of the variables.

Independent variables: 1) Technology R \& D human resource input (X1): the number of people involved in the research, and only scientists and engineers are counted, excluding people who are in charge of education; 2) R \& D funding input: this input is divided into three types including input for basic research, application research and experience research, respectively defined as X2.1, X2.2, $\mathrm{X} 2.3$ (unit: a thousand yuan). And the overall research funding input is defined as X2; 3) Popularization funding input: this part consists of two parts. One is the $\mathrm{R} \& \mathrm{D}$ transfer funding input, referring to the cost of spreading the research achievements (unit: a thousand yuan), which is defined as X3.1. Another one is technology transfer service funding input, which is relevant cost for better spreading the technologies, includes indirect cost such as installation, maintenance and rebuilding (unit: a thousand yuan), and is defined as X3.2. The overall 
input is defined as X3.

Dependent variables: 1) the number of patents (Y1): the overall number of the patents generated from the scientific research, including inventions, practical new modes and appearance design; 2) the number of papers (Y2): the overall number of published papers generated from the scientific research, including papers in Chinese and foreign languages; 3 ) Real income of the year (Y3): all the incomes generated from the technological achievements such as signing transfer contracts (unit: a thousand yuan). The real income of the year is taken as the data because the specific transfer method would be affected by the market situation.

Regulating variables: 1) the number of funding project ( $\mathrm{Z} 1)$ : since the universities and research institutes are the main body of technological transfer, the main approach of scientific research is funding project. Therefore the number of the projects would influence the outcome to a certain extent; 2) the cost of project research (Z2): the total cost used to complete the projects. The data of the real cost is adopted including the cost of student education and skill training. Theoretically, this cost is correlated with the R \& D ability because higher cost should be able to increase the output due to the long period of scientific research; 3) human resource input of technology transfer service (Z3): the number of staff who are involved in the transfer and application all the time, including technology transfer specialists, negotiating staff and legal personnel.

\subsection{Data Preprocessing}

Data processing is conducted towards the three sub-variables of research funding input (X2) and the two sub-variables of popularization funding input (X3). Firstly, SPSS is adopted to carry out reliability test for basic research, application research and experience research. The result is that the reliability being larger than 0.7 , which means the selection of variables is reasonable. Then the reliability test is also carried out for research funding input and transfer funding input, and the reliability is also larger than 0.7 showing the effectiveness of the selection.

On the basis of reliability test, KMO test and factor analysis are conducted towards the sub-variables for X2 and X3. The KMO test is used to test the correlation between different indexes, and its value is normally between 0 and 1 . The higher the KMO is, the stronger the correlation is, and the results of factor analysis and principal component analysis would be better. Kaiser (1974) believes that KMO being under 0.49 is a bad result while it being between 0.5 and 0.79 is acceptable. If the $\mathrm{KMO}$ is higher than 0.8 , then it's a very good result. As is shown in the graph, the KMO of X2.1, X2.2, X2.3 is 0.735 , which is an acceptable result. It means that a new representative variable $\mathrm{X} 2$ can be obtained to represent X2.1, X2.2 and X2.3 through principal component analysis (PCA).

The KMO of X3.1 and X3.2 is 0.5, which is not good but can still be accepted. PCA is also conducted for the two sub-variables and a new representative variable $\mathrm{X} 3$ is achieved. 


\subsection{Results of Case Study}

Since there are quite a lot variables, the ones correlated with the dependent variables are screened out firstly and regression relationships are established between them. The influence of regulating variables is also analyzed. The independent variables' impacts on the number of patents (Y1) are assessed firstly and the detailed analysis process is only shown for this part. For other parts of analysis, only the results are demonstrated. The variable screening function of Stata 14.0 is adopted to analyze $\mathrm{X} 2$ and $\mathrm{X} 3$ and then the sub-variables. Only part of the results is listed and analyzed due to the complexity of the whole process.

After calculating the overall variables X2 and X3 using Stata, the hierarchical regression is carried out to add mainly assessed variables into Model 1, corresponding regulating variables into Model 2, and interaction of regulating and corresponding main variables into Model 3. The following table shows the impact of regulating variable $\mathrm{Z} 1$ (the number of funding project) on $\mathrm{Y} 1$ (the number of patents), which shown as Table 1 .

It is indicated that the human resource input is significantly positively correlated with the number of funding project. When the funding project number rises, the patent number can be increased by adding more human resource into technological R \& D, as Table 2, which can also show that the staff number also influences the patent outcome.

Table 1. How funding project number regulates the impact on patent number caused by R \& D human resource input.

\begin{tabular}{cccc}
\hline Variables & Model 1 & Model 2 & Model 3 \\
\hline R \& D human resource input & $0.5013^{* *}$ & 0.0839 & $0.3782^{\star *}$ \\
R \& D funding input & 0.2516 & $0.9381^{* *}$ & -0.0881 \\
Popularization funding input & 0.2472 & $0.8250^{* *}$ & 0.0645 \\
Number of funding project & & $0.9018^{* *}$ & 0.51947 \\
Number of funding project* R \& D human resource input & & & $0.4419^{* * *}$ \\
R2 & 0.9458 & 0.9666 & 0.9888 \\
Adjust-R2 & 0.9334 & 0.9544 & 0.9832 \\
\hline
\end{tabular}

${ }^{\star} p<0.1,{ }^{* *} p<0.05,{ }^{* * *} p<0.01$.

Table 2. How funding project number regulates the impact on patent number caused by $\mathrm{R} \& \mathrm{D}$ funding input.

\begin{tabular}{cccc}
\hline Variables & Model 1 & Model 2 & Model 3 \\
\hline R \& D human resource input & $0.5013^{\star *}$ & 0.0839 & 0.2903 \\
R \& D funding input & 0.2516 & $0.9381^{\star *}$ & 0.4281 \\
Popularization funding input & 0.2472 & $0.8250^{\star *}$ & 0.4009 \\
Number of funding project & & $0.9018^{\star *}$ & -0.1968 \\
Number of funding project * R \& D funding input & & & $0.2391^{\star *}$ \\
R2 & 0.9458 & 0.9666 & 0.9811 \\
Adjust-R2 & 0.9334 & 0.9544 & 0.9717 \\
\hline
\end{tabular}

${ }^{*} p<0.1,{ }^{* *} p<0.05,{ }^{* * *} p<0.01$. 
It is shown in Table 3 that the result is statistically significant and the number of funding project has positive regulating effect which means that when the funding project number rises, the patent number can be increased by adding more funding cost into technological R \& D.

The value of $\mathrm{P}$ is smaller than 0.05 , which shows a significant positive regulating effect of funding project number. Therefore, when the funding project number rises, the patent number can be increased by adding more popularization funding cost.

According to the analysis above, the positive regulating effect of funding project number is shown on human resource input, funding input and popularization funding input. The reasons include: 1) Since scientific research is still the dominant leading factor in the outcome assessment, increasing the funding input for research would definitely bring about positive effects. The number of funding projects can also lead to such positive influences correspondingly; 2) Agricultural science not only needs theoretical research but also requires experience, which makes it practical and sometimes can be directly applied to real practice. And adding more human resource in the transfer service can realize the application more easily. The knowledge gained during the practice can deepen the theoretical research in return; 3) The need of practice in this field is the reason why increasing relevant input and service staff can raise the outcome.

The regulating effects of $\mathrm{Z} 2$ and $\mathrm{Z} 3$ on the models are also analyzed using the same method, which shown as Table 4 and Table 5. The results in the following tables demonstrate that the cost of project research can positively regulate the influences on patent number of $\mathrm{R} \& \mathrm{D}$ human resource input, funding input and popularization funding input. This is caused by similar reasons mentioned above. Practice is more and more important in scientific research, therefore with the increase of human resource and funding input, the research can be better supported and generate more patent outcome. With the rise of project research cost, the popularization funding input can also positively influence the quality and quantity of patents although it cannot lead to outcomes directly, show as Table 6.

Table 3. How funding project number regulates the impact on patent number caused by $\mathrm{R} \& \mathrm{D}$ popularization funding input.

\begin{tabular}{|c|c|c|c|}
\hline Variables & Model 1 & Model 2 & Model 3 \\
\hline $\mathrm{R} \& \mathrm{D}$ human resource input & $0.5013^{\star *}$ & 0.0839 & 0.3458 \\
\hline $\mathrm{R}$ \& $\mathrm{D}$ funding input & 0.2516 & $0.9381^{\star *}$ & 0.4623 \\
\hline Popularization funding input & 0.2472 & $0.8250^{\star *}$ & 0.3276 \\
\hline Number of funding project & & $0.9018^{\star *}$ & -0.1932 \\
\hline Number of funding project ${ }^{*}$ Popularization funding input & & & $0.1828^{* *}$ \\
\hline $\mathrm{R} 2$ & 0.9458 & 0.9666 & 0.9785 \\
\hline Adjust-R2 & 0.9334 & 0.9544 & 0.9677 \\
\hline
\end{tabular}

${ }^{\star} p<0.1,{ }^{* *} p<0.05,{ }^{* * *} p<0.01$. 
Table 4. How project research cost regulates the impact on patent number caused by R \& D human resource input.

\begin{tabular}{cccc}
\hline Variables & Model 1 & Model 2 & Model 3 \\
\hline R \& D human resource input & $0.5013^{* *}$ & $0.5012^{* *}$ & 0.1565 \\
R \& D funding input & 0.2516 & 0.2560 & 0.4019 \\
Popularization funding input & 0.2472 & 0.2638 & 0.0853 \\
Cost of project research & & -0.0209 & 0.1965 \\
R2 & & & $0.3087^{\star * *}$ \\
Adjust-R2 & 0.9458 & 0.9459 & 0.9868 \\
\hline
\end{tabular}

${ }^{\star} p<0.1,{ }^{* *} p<0.05,{ }^{* *} p<0.01$.

Table 5. How project research cost regulates the impact on patent number caused by $\mathrm{R} \&$ $\mathrm{D}$ transfer funding input.

\begin{tabular}{cccc}
\hline Variables & Model 1 & Model 2 & Model 3 \\
\hline R \& D human resource input & $0.5013^{* *}$ & $0.5012^{* *}$ & $0.2653^{* *}$ \\
R \& D funding input & 0.2516 & 0.2560 & 0.3128 \\
Popularization funding input & 0.2472 & 0.2638 & -0.2565 \\
Cost of project research & & -0.0209 & -0.1932 \\
Cost of project research ${ }^{*}$ \& \& D funding input & & & $0.2858^{* *}$ \\
R2 & 0.9458 & 0.9459 & 0.9880 \\
Adjust-R2 & 0.9334 & 0.9262 & 0.9820 \\
\hline
\end{tabular}

${ }^{*} p<0.1,{ }^{* *} p<0.05,{ }^{* * *} p<0.01$.

Table 6. How project research cost regulates the impact on patent number caused by R \& D popularization funding input.

\begin{tabular}{cccc}
\hline Variables & Model 1 & Model 2 & Model 3 \\
\hline R \& D human resource input & $0.5013^{\star *}$ & $0.5012^{\star *}$ & $0.3432^{\star *}$ \\
R \& D funding input & 0.2516 & 0.2560 & 0.2880 \\
Popularization funding input & 0.2472 & 0.2638 & -0.4800 \\
Cost of project research & & -0.0209 & 0.7580 \\
Cost of project research* Popularization funding input & & & $0.2270^{* * *}$ \\
R2 & 0.9458 & 0.9459 & 0.9851 \\
Adjust-R2 & 0.9334 & 0.9262 & 0.9777 \\
\hline
\end{tabular}

${ }^{*} p<0.1,{ }^{* *} p<0.05,{ }^{* *} p<0.01$.

The analysis of $\mathrm{Z} 3$ also shows that the human resource input of technology transfer service can positively regulate the impacts of human resource input, funding input and popularization funding input on the patent number. It can be concluded that by adding more staff to the transfer service, the technological knowledge is more widely spread therefore promote relevant research in agricultural intellectual properties (in Tables 7-9). 
Table 7. How human resource input of technology transfer service regulates the impact on patent number caused by R \& D human resource input.

\begin{tabular}{cccc}
\hline Variables & Model 1 & Model 2 & Model 3 \\
\hline R \& D human resource input & $0.5013^{* *}$ & $0.5094^{* *}$ & $0.4593^{* *}$ \\
R \& D funding input & 0.2516 & 0.2181 & 0.5004 \\
Popularization funding input & 0.2472 & 0.2693 & -0.0162 \\
Technology transfer service staff & & -0.0209 & 0.0612 \\
Technology transfer service staff* R \& D human resource input & & & $0.1867^{*}$ \\
R2 & 0.9458 & 0.9462 & 0.9868 \\
Adjust-R2 & 0.9334 & 0.9267 & 0.9802 \\
\hline
\end{tabular}

${ }^{\star} p<0.1,{ }^{* *} p<0.05,{ }^{* * *} p<0.01$.

Table 8. How human resource input of technology transfer service regulates the impact on patent number caused by $\mathrm{R} \& \mathrm{D}$ transfer funding input.

\begin{tabular}{cccc}
\hline Variables & Model 1 & Model 2 & Model 3 \\
\hline R \& D human resource input & $0.5013^{* \star}$ & $0.5094^{\star *}$ & $0.5299^{\star *}$ \\
R \& D funding input & 0.2516 & 0.2181 & 0.4263 \\
Popularization funding input & 0.2472 & 0.2693 & -0.0321 \\
Technology transfer service staff & & -0.0209 & 0.0764 \\
Technology transfer service staff* R \& D funding input & & & $0.1835^{*}$ \\
R2 & 0.9458 & 0.9462 & 0.9632 \\
Adjust-R2 & 0.9334 & 0.9267 & 0.9448 \\
\hline
\end{tabular}

${ }^{\star} p<0.1,{ }^{* *} p<0.05,{ }^{* * *} p<0.01$.

Table 9. How human resource input of technology transfer service regulates the impact on patent number caused by $\mathrm{R} \& \mathrm{D}$ popularization funding input.

\begin{tabular}{cccc}
\hline variables & Model 1 & Model 2 & Model 3 \\
\hline R \& D human resource input & $0.5013^{* *}$ & $0.5094^{* *}$ & $0.5535^{* *}$ \\
R \& D funding input & 0.2516 & 0.2181 & 0.3332 \\
Popularization funding input & 0.2472 & 0.2693 & 0.0175 \\
Technology transfer service staff & & -0.0209 & 0.0871 \\
Technology transfer service staff* Popularization funding input & & & $0.1948^{* *}$ \\
R2 & 0.9458 & 0.9462 & 0.9690 \\
Adjust-R2 & 0.9334 & 0.9267 & 0.9535 \\
\hline
\end{tabular}

${ }^{\star} p<0.1,{ }^{* *} p<0.05,{ }^{* * *} p<0.01$.

The effects of the regulating variables on the relationship between the independent variables and the number of published papers are analyzed as well. The result as Table 10 and Table 11 shows that only the number of funding projects can have positive regulating effect. It means that with the increase of funding projects, the number of published papers would rise when adding $\mathrm{R} \& \mathrm{D}$ funding 
Table 10. How funding project number regulates the impact on paper number caused by $\mathrm{R} \& \mathrm{D}$ transfer funding input.

\begin{tabular}{cccc}
\hline variables & Model 1 & Model 2 & Model 3 \\
\hline R \& D human resource input & -0.1914 & 0.1109 & -0.2266 \\
R \& D funding input & $0.7674^{*}$ & 0.2700 & 1.1040 \\
Popularization funding input & 0.3828 & -0.0358 & 0.6577 \\
Number of funding project & & 0.6534 & -0.4955 \\
Number of funding project* R \& D funding input & & & $0.3901^{\star * *}$ \\
R2 & 0.9383 & 0.9492 & 0.9811 \\
$\Delta \mathrm{R} 2$ & 0.9229 & 0.9307 & 0.9717 \\
\hline
\end{tabular}

${ }^{\star} p<0.1,{ }^{* *} p<0.05,{ }^{* * *} p<0.01$.

Table 11. How funding project number regulates the impact on paper number caused by $\mathrm{R} \& \mathrm{D}$ popularization funding input.

\begin{tabular}{cccc}
\hline variables & Model 1 & Model 2 & Model 3 \\
\hline R \& D human resource input & -0.1914 & 0.1109 & -0.3459 \\
R \& D funding input & $0.7674^{*}$ & 0.2700 & 1.0983 \\
Popularization funding input & 0.3828 & -0.0358 & 0.8313 \\
Number of funding project & & 0.6534 & -0.5823 \\
Number of funding project* Popularization funding input & & & $0.3189^{* *}$ \\
R2 & 0.9383 & 0.9492 & 0.9854 \\
$\Delta \mathrm{R} 2$ & 0.9229 & 0.9307 & 0.9781 \\
\hline
\end{tabular}

${ }^{\star} p<0.1,{ }^{* *} p<0.05,{ }^{* *} p<0.01$.

input and popularization input. It is because of similar reasons, for example, the number of papers is still the mainly assessed index and projects are major carriers of the research missions of universities, which therefore become a crucial factor.

And after analyzing the real income of the year created by technology transfer, no significant correlation is demonstrated. The highest correlation value reaches 0.17 when regulating the human resource input, which is close to the significant value. One of the reasons behind this result may be that the staff number is calculated too broadly without specifying the service types. Another possible reason is that the real income is calculated by the money received in that year however in the reality, the money for one contract can be paid for several times and may be received in another year, which makes it difficult to be clarified.

After the analysis of the overall variables, the sub-variables are also studied. Firstly, the correlation between the independent and dependent variables are evaluated and then regression analysis is conducted before discussing the impacts of the variables in tablet, using Std. Coeffi short for standardized Coefficients. Shown as Table 12. 
Table 12. Variables that have correlation with Y1.

\begin{tabular}{|c|c|c|c|c|c|c|c|c|}
\hline \multicolumn{9}{|c|}{ Coefficients $^{\mathrm{a}}$} \\
\hline & \multirow{2}{*}{ Model } & \multicolumn{2}{|c|}{ UnStd. Coeffi } & \multirow{2}{*}{$\begin{array}{l}\begin{array}{l}\text { Std. } \\
\text { Coeffi }\end{array} \\
\text { Beta }\end{array}$} & \multirow{2}{*}{$\mathrm{t}$} & \multirow{2}{*}{ Sig. } & \multicolumn{2}{|c|}{$\begin{array}{l}95.0 \% \text { Confidence } \\
\text { Interval for B }\end{array}$} \\
\hline & & B & Std. Error & & & & Lower B & Upper B \\
\hline \multirow{2}{*}{1} & (Constant) & -2737.856 & 502.919 & & -5.444 & 0.000 & -3816.510 & -1659.202 \\
\hline & $\mathrm{X} 2.3$ & 0.021 & 0.002 & 0.964 & 13.608 & 0.000 & 0.018 & 0.025 \\
\hline \multirow{3}{*}{2} & (Constant) & -16926.384 & 3948.596 & & -4.287 & 0.001 & -25456.807 & -8395.961 \\
\hline & $\mathrm{X} 2.3$ & 0.013 & 0.003 & 0.574 & 4.794 & 0.000 & 0.007 & 0.019 \\
\hline & $\mathrm{X} 1$ & 1.455 & 0.403 & 0.433 & 3.609 & 0.003 & 0.584 & 2.326 \\
\hline
\end{tabular}

${ }^{a}$ Dependent Variable: PATENT; ${ }^{*} p<0.1,{ }^{* *} p<0.05,{ }^{* * *} p<0.01$.

It is shown that $\mathrm{R} \& \mathrm{D}$ human resource input and experience research input both have positive impacts on the patent outcome. Therefore X1 and X2.1 are put together and regulating variables $\mathrm{Z1}, \mathrm{Z} 2$ and $\mathrm{Z} 3$ are introduced to study their influences on $Y 1$, as Tables 13-15. The result shows an obvious regulating effect of $\mathrm{Z} 1, \mathrm{Z} 2$ and $\mathrm{Z} 3$. When $\mathrm{Z}$ is not adjusted, there is a significant positive correlation between experience research input, technology $\mathrm{R} \& \mathrm{D}$ human resource input and Y1, the regression coefficients of which are respectively 0.013 and 1.455, with $\mathrm{P}$ value being smaller than 0.05 . And the models are statistically acceptable $(p<0.001)$ with the value of $\mathrm{R}^{2}$ being larger than 0.9 . This demonstrates a positive effect of funding project number, project research cost and human resource input of technology transfer service, which means that by increasing resource input, the positive influence caused by $\mathrm{R} \& \mathrm{D}$ human resource and experience research input can be enlarged and bring more benefits to the innovation achievements.

On the basis of the analysis above, add Z1, Z2 and Z3 into the models and compare the new results with the original ones as is shown in Table 16. Any two of the three regulating variables can have positive influences on the model. The positive correlation between experience research input or technology $\mathrm{R} \& \mathrm{D}$ human resource input and Y1 still exists after further adjusting the combination of the regulating variables and there is no obvious change of correlation coefficient with $\mathrm{P}$ value being smaller than 0.05 . However, the significance of $\mathrm{R} \& \mathrm{D}$ human resource input does not exist anymore when the three regulating variables are all added into the model. One possible reason is that when the resource offered by the government is allocated into too many aspects, the cost of technology transfer increases correspondingly therefore a decrease of output is caused. Besides, the agricultural technology achievements cannot be converted into productivity in a short period due to the pilot test and an observation period of one year. As a result, adding cost in too many aspects can lead to a waste of resource in a certain period.

Carry out the same analysis and it is found that only R \& D human resource input (X1) and basic research funding input (X2.1) are significantly correlated 
Table 13. Result obtained after adding Z1.

\begin{tabular}{|c|c|c|c|c|c|c|c|}
\hline \multicolumn{8}{|c|}{ Coefficients $^{\mathrm{a}}$} \\
\hline \multirow{2}{*}{ Model } & \multicolumn{2}{|c|}{ Un std. Coeffi } & \multirow{2}{*}{$\begin{array}{c}\text { Std. } \\
\text { Coeffi }\end{array}$} & \multirow{2}{*}{$\mathrm{t}$} & \multirow{2}{*}{ Sig. } & \multicolumn{2}{|c|}{$\begin{array}{l}95.0 \% \text { Confidence } \\
\text { Interval for B }\end{array}$} \\
\hline & $\mathrm{B}$ & Std. Error & & & & Lower Bound & Upper Bound \\
\hline (Constant) & -15300.33 & 3982.0 & & -3.84 & 0.002 & -23976.517 & -6624.156 \\
\hline $\begin{array}{l}\text { R \& D human } \\
\text { resource input }\end{array}$ & 1.315 & 0402 & 0.391 & 3.27 & 0.007 & 0.440 & 2.190 \\
\hline $\begin{array}{l}\text { experience } \\
\text { research input }\end{array}$ & 0.018 & 0.004 & 0.800 & 4.03 & 0.002 & 0.008 & 0.027 \\
\hline $\begin{array}{c}\text { number of } \\
\text { funding project }\end{array}$ & -0.434 & 0.309 & -0.202 & -1.40 & 0.186 & -1.107 & 0.240 \\
\hline
\end{tabular}

${ }^{a}$ Dependent Variable: PATENT; ${ }^{*} p<0.1,{ }^{* *} p<0.05,{ }^{* * *} p<0.01$.

Table 14. Result obtained after adding Z2.

\begin{tabular}{|c|c|c|c|c|c|c|c|c|}
\hline \multicolumn{9}{|c|}{ Coefficients $^{\mathrm{a}}$} \\
\hline & \multirow{2}{*}{ Model } & \multicolumn{2}{|c|}{ Unstd. Coeffi } & \multirow{2}{*}{$\begin{array}{c}\text { Std. Coeffi } \\
\text { Beta }\end{array}$} & \multirow{2}{*}{$\mathrm{t}$} & \multirow{2}{*}{ Sig. } & \multicolumn{2}{|c|}{$\begin{array}{c}95.0 \% \text { Confidence } \\
\text { Interval for B }\end{array}$} \\
\hline & & B & Std. Error & & & & Lower B & Upper B \\
\hline & (Constant) & -17030 & 4130.42 & & -4.12 & 0.001 & -26030.2 & -8031.4 \\
\hline & $\begin{array}{l}\mathrm{R} \& \mathrm{D} \text { human } \\
\text { resource input }\end{array}$ & 1.43 & 0.434 & 0.425 & 3.292 & 0.006 & 0.484 & 2.377 \\
\hline 1 & $\begin{array}{c}\text { experience } \\
\text { research input }\end{array}$ & 0.013 & 0.003 & 0.579 & 4.595 & 0.001 & 0.007 & 0.019 \\
\hline & $\begin{array}{l}\text { human resource } \\
\text { input of technology } \\
\text { transfer service }\end{array}$ & 0.108 & 0.503 & 0.012 & 0.216 & 0.833 & -0.988 & 1.204 \\
\hline
\end{tabular}

a Dependent Variable: PATENT; ${ }^{*} p<0.1,{ }^{* *} p<0.05,{ }^{* * *} p<0.01$.

Table 15. Result obtained after adding Z3.

\begin{tabular}{|c|c|c|c|c|c|c|c|c|}
\hline \multicolumn{9}{|c|}{ Coefficients $^{\mathrm{a}}$} \\
\hline & \multirow{2}{*}{ Model } & \multicolumn{2}{|c|}{ Unstd. Coeffi } & Std. Coeffi & \multirow{2}{*}{$\mathrm{t}$} & \multirow{2}{*}{ Sig. } & \multicolumn{2}{|c|}{$\begin{array}{c}95.0 \% \text { Confidence } \\
\text { Interval for B }\end{array}$} \\
\hline & & B & Std. Error & Beta & & & Lower B & Upper B \\
\hline \multirow{4}{*}{1} & (Constant) & -17030 . & 4130.42 & & -4.12 & 0.001 & -26030.2 & -8031.4 \\
\hline & $\begin{array}{l}\mathrm{R} \& \mathrm{D} \text { human } \\
\text { resource input }\end{array}$ & 1.43 & 0.434 & 0.425 & 3.292 & 0.006 & 0.484 & 2.377 \\
\hline & $\begin{array}{c}\text { experience } \\
\text { research input }\end{array}$ & 0.013 & 0.003 & 0.579 & 4.595 & 0.001 & 0.007 & 0.019 \\
\hline & $\begin{array}{l}\text { human resource } \\
\text { input of technology } \\
\text { transfer service }\end{array}$ & 0.108 & 0.503 & 0.012 & 0.216 & 0.833 & -0.988 & 1.204 \\
\hline
\end{tabular}

${ }^{a}$ Dependent Variable: PATENT; ${ }^{\star} p<0.1,{ }^{* *} p<0.05,{ }^{* * *} p<0.01$. 
Table 16. Influences of the regulating variables on the model after being adjusted.

\begin{tabular}{|c|c|c|c|c|c|c|c|c|c|}
\hline \multirow{2}{*}{$\begin{array}{l}\text { Adjusted } \\
\text { variables }\end{array}$} & \multirow{2}{*}{ variables } & \multicolumn{3}{|c|}{ Coefficients } & \multirow[t]{2}{*}{$\mathrm{t}$} & \multirow[t]{2}{*}{$p$-value } & \multicolumn{2}{|c|}{$\begin{array}{c}95.0 \% \\
\text { Confid for B }\end{array}$} & \multirow{2}{*}{$\begin{array}{c}\begin{array}{c}\text { Model } \\
\text { test }\end{array} \\
\text { R-square }\end{array}$} \\
\hline & & $\begin{array}{l}\text { Unstd. } \\
\text { Coeffi }\end{array}$ & $\begin{array}{l}\text { Std. } \\
\text { Error }\end{array}$ & $\begin{array}{c}\text { Std. } \\
\text { Coeffi }\end{array}$ & & & Lower B & Upper B & \\
\hline \multirow{2}{*}{ No } & $\mathrm{X} 2.3$ & 0.013 & 0.003 & 0.574 & 4.794 & $0.000^{* * *}$ & 0.007 & 0.019 & \multirow{2}{*}{0.965} \\
\hline & $\mathrm{X} 1$ & 1.455 & 0.403 & 0.433 & 3.609 & $0.003^{\star *}$ & 0.584 & 2.326 & \\
\hline \multirow{2}{*}{$\mathrm{Z} 1$} & $\mathrm{X} 2.3$ & 0.018 & 0.004 & 0.800 & 4.037 & $0.002^{\star *}$ & 0.008 & 0.027 & \multirow{2}{*}{0.970} \\
\hline & $\mathrm{X} 1$ & 1.315 & 0.402 & 0.391 & 3.275 & $0.007^{* *}$ & 0.440 & 2.190 & \\
\hline \multirow{2}{*}{$\mathrm{Z} 2$} & $\mathrm{X} 2.3$ & 0.015 & 0.005 & 0.672 & 2.764 & $0.017^{\star}$ & 0.003 & 0.027 & \multirow{2}{*}{0.966} \\
\hline & $\mathrm{X} 1$ & 1.469 & 0.417 & 0.437 & 3.523 & $0.004^{* *}$ & 0.560 & 2.377 & \\
\hline \multirow{2}{*}{$\mathrm{Z} 3$} & $\mathrm{X} 2.3$ & 0.013 & 0.003 & 0.579 & 4.595 & $0.001^{* *}$ & 0.007 & 0.019 & \multirow{2}{*}{0.965} \\
\hline & $\mathrm{X} 1$ & 1.430 & 0.434 & 0.425 & 3.292 & $0.006^{* *}$ & 0.484 & 2.377 & \\
\hline \multirow{2}{*}{$\mathrm{Z} 1+\mathrm{Z} 2$} & $\mathrm{X} 2.3$ & 0.014 & 0.005 & 0.650 & 2.965 & $0.013^{\star}$ & 0.004 & 0.025 & \multirow{2}{*}{0.974} \\
\hline & $\mathrm{X} 1$ & 1.023 & 0.439 & 0.304 & 2.330 & $0.040^{*}$ & 0.057 & 1.989 & \\
\hline \multirow{2}{*}{$\mathrm{Z} 1+\mathrm{Z} 3$} & $\mathrm{X} 2.3$ & 0.019 & 0.005 & 0.849 & 3.946 & $0.002^{* *}$ & 0.008 & 0.029 & \multirow{2}{*}{0.971} \\
\hline & $\mathrm{X} 1$ & 1.214 & 0.437 & 0.361 & 2.780 & $0.018^{\star}$ & 0.253 & 2.176 & \\
\hline \multirow{2}{*}{$\mathrm{Z} 2+\mathrm{Z} 3$} & $\mathrm{X} 2.3$ & 0.015 & 0.006 & 0.695 & 2.646 & $0.023^{\star}$ & 0.003 & 0.028 & \multirow{2}{*}{0.966} \\
\hline & $\mathrm{X} 1$ & 1.432 & 0.448 & 0.426 & 3.192 & $0.009^{* *}$ & 0.445 & 2.419 & \\
\hline \multirow{2}{*}{ Z1 Z2 Z3 } & $\mathrm{X} 2.3$ & 0.016 & 0.005 & 0.699 & 3.025 & $0.013^{*}$ & 0.004 & 0.027 & \multirow{2}{*}{0.976} \\
\hline & $\mathrm{X} 1$ & 0.898 & 0.473 & 0.267 & 1.901 & 0.087 & -0.155 & 1.951 & \\
\hline
\end{tabular}

${ }^{\star} p<0.1,{ }^{* *} p<0.05,{ }^{* * *} p<0.01$.

with the number of published papers (Y2). And only the R \& D human resource input (X1) is correlated with the real income of the year (Y3). Add the regulating variables Z1, Z2 and Z3 into the model and further analyze the relationships between the variables to get the following results, shown as Table 17.

From the table above, it is demonstrated that before adjusting the regulating variables, only the basic research input (X2.1) is positively correlated with Y2 (correlation coefficient is 0.028 ), and the full researcher number is negatively correlated with Y2 (correlation coefficient is -7.015 ), with $\mathrm{P}$ values both below 0.05 . And the model is statistically significant $(p<0.001)$ with $\mathrm{R}^{2}$ being larger than 0.9 . The correlation only exists after adjusting $\mathrm{Z} 3$ and no correlations still exist after adjusting other regulating variables. Conclusion can be drawn that with the increase of human resource input of technology transfer service, the basic research funding input and human resource input can have positive impacts on the number of papers. This is because these independent variables are beneficial to theoretical research, and on the basis of that, adding more human resource in transfer service can help people achieve deeper understanding of technology innovation and further promote its development. There are other real cases that can prove the conclusion.

As to $\mathrm{Y} 3$, only the R \& D human resource input is correlated with it. After adjusting the regulating factors, as Table 18 . It is found that the positive correla- 
Table 17. The relationship between Y2 and other variables.

\begin{tabular}{|c|c|c|c|c|c|c|c|c|}
\hline \multirow{2}{*}{$\begin{array}{l}\text { Adjusted } \\
\text { variables }\end{array}$} & \multirow{2}{*}{ variables } & \multicolumn{3}{|c|}{ Coefficients } & \multirow{2}{*}{$\mathrm{t}$} & \multirow{2}{*}{$p$-value } & \multicolumn{2}{|c|}{$95.0 \%$ Confid } \\
\hline & & Unstd. Coeffi & Std. Error & Std. Coeffi & & & Lower B & Upper B \\
\hline \multirow{2}{*}{ No } & $\mathrm{X} 2.1$ & 0.028 & 0.004 & 1.435 & 7.255 & $0.000^{* * *}$ & 0.019 & 0.036 \\
\hline & $\mathrm{X} 1$ & -7.015 & 2.761 & -0.503 & -2.541 & $0.025^{*}$ & -12.979 & -1.050 \\
\hline \multirow{2}{*}{$\mathrm{Z} 1$} & $\mathrm{X} 2.1$ & -2.349 & 3.887 & -0.168 & -0.604 & 0.557 & -10.817 & 6.119 \\
\hline & $\mathrm{X} 1$ & 0.014 & 0.009 & 0.731 & 1.542 & 0.149 & -0.006 & 0.034 \\
\hline \multirow{2}{*}{$\mathrm{Z} 2$} & $\mathrm{X} 1$ & -4.980 & 2.930 & -0.357 & -1.700 & 0.115 & -11.365 & 1.404 \\
\hline & $\mathrm{X} 2.1$ & 0.017 & 0.008 & 0.881 & 2.188 & $0.049^{\star}$ & 0.000 & 0.034 \\
\hline \multirow{2}{*}{$\mathrm{Z3}$} & $\mathrm{X} 1$ & -6.183 & 2.796 & -0.443 & -2.211 & $0.047^{\star}$ & -12.276 & -0.091 \\
\hline & $\mathrm{X} 2.1$ & 0.027 & 0.004 & 1.398 & 7.111 & $0.000^{\star * *}$ & 0.019 & 0.035 \\
\hline \multirow{2}{*}{$\mathrm{Z} 1+\mathrm{Z} 2$} & $\mathrm{X} 1$ & -3.061 & 4.260 & -0.219 & -0.718 & 0.487 & -12.437 & 6.315 \\
\hline & $\mathrm{X} 2.1$ & 0.014 & 0.009 & 0.713 & 1.453 & 0.174 & -0.007 & 0.034 \\
\hline \multirow{2}{*}{$\mathrm{Z} 1+\mathrm{Z} 3$} & $\mathrm{X} 1$ & 3.627 & 3.433 & 0.260 & 1.057 & 0.313 & -3.929 & 11.183 \\
\hline & $\mathrm{X} 2.1$ & 0.000 & 0.008 & 0.026 & 0.062 & 0.952 & -0.017 & 0.018 \\
\hline \multirow{2}{*}{$\mathrm{Z} 2+\mathrm{Z} 3$} & $\mathrm{X} 1$ & -3.150 & 2.812 & -0.226 & -1.120 & 0.287 & -9.338 & 3.039 \\
\hline & $\mathrm{X} 2.1$ & 0.013 & 0.007 & 0.655 & 1.714 & 0.115 & -0.004 & 0.029 \\
\hline \multirow{2}{*}{ Z1 Z2Z3 } & $\mathrm{X} 1$ & 3.616 & 3.908 & 0.259 & 0.925 & 0.377 & -5.092 & 12.325 \\
\hline & $\mathrm{X} 2.1$ & 0.000 & 0.008 & 0.026 & 0.059 & 0.954 & -0.018 & 0.019 \\
\hline
\end{tabular}

${ }^{*} p<0.1,{ }^{* *} p<0.05,{ }^{* *} p<0.01$.

Table 18. The relationship between Y3 and other variables.

\begin{tabular}{ccccccccc}
\hline \multirow{2}{*}{$\begin{array}{c}\text { Adjusted } \\
\text { variables }\end{array}$} & variables & \multicolumn{5}{c}{ Coefficients } & & Mo test \\
\cline { 3 - 5 } & & Unstd. Coeffi & Std. Err & Std. Coeffi & & $p$-value & R-square \\
\hline No & $\mathrm{X} 1$ & 11.184 & 0.801 & 0.966 & 13.962 & $0.000^{* * *}$ & 0.933 \\
$\mathrm{Z} 1$ & $\mathrm{X} 1$ & 10.573 & 1.376 & 0.913 & 7.686 & $0.000^{* * *}$ & 0.935 \\
$\mathrm{Z} 2$ & $\mathrm{X} 1$ & 9.230 & 1.653 & 0.797 & 5.583 & $0.000^{* * *}$ & 0.941 \\
$\mathrm{Z} 3$ & $\mathrm{X} 1$ & 11.491 & 0.826 & 0.992 & 13.911 & $0.000^{* * *}$ & 0.940 \\
$\mathrm{Z} 1+\mathrm{Z} 2$ & $\mathrm{X} 1$ & 6.647 & 1.613 & 0.574 & 4.122 & $0.001^{* * *}$ & 0.965 \\
$\mathrm{Z} 1+\mathrm{Z} 3$ & $\mathrm{X} 1$ & 10.816 & 1.364 & 0.934 & 7.932 & $0.000^{* * *}$ & 0.942 \\
$\mathrm{Z} 2+\mathrm{Z} 3$ & $\mathrm{X} 1$ & 9.556 & 1.640 & 0.825 & 5.827 & $0.000^{* * *}$ & 0.948 \\
$\mathrm{Z} 1 \mathrm{Z} 2 \mathrm{Z} 3$ & $\mathrm{X} 1$ & 7.036 & 1.682 & 0.608 & 4.183 & $0.002^{* * *}$ & 0.967 \\
\hline
\end{tabular}

${ }^{*} p<0.1,{ }^{* *} p<0.05,{ }^{* * *} p<0.01$.

tion between full researcher number and $\mathrm{Y} 3$ still exists, and there is no obvious change of regression coefficient unless the combinations of $\mathrm{Z} 1+\mathrm{Z} 2$ and $\mathrm{Z} 1+\mathrm{Z} 3$ are adjusted. This result means that only human resource input can positively influence the real income generated by technology transfer.

\subsection{Conclusions}

According to the analysis, both the sub-variables and the overall variables can 
influence the technology transfer performance and all of them should be taken into consideration when allocating resource. It is found that the researcher number and experience research funding input have positive impacts on patent outcome, which further proves that agricultural technology is a practical field and requires experience. As to the number of published papers, it is only related to the basic research funding input and researcher number, and only the human resource input of technology transfer service has positive regulating effect on the relationship. This result also demonstrates that although innovation is the foundation of research achievement, human resource is needed to spread these knowledge and technologies. The real income of the year is only related to the $\mathrm{R}$ $\& \mathrm{D}$ human resource input, but the funding project number, cost of project research and human resource of transfer service can all positively regulate the relationship. It is seen that the $\mathrm{R} \& \mathrm{D}$ human resource input is correlated to all of the dependent variables including patent number, paper number and real income of the year. Therefore, the key strategy to improve technology innovation and transfer is to raise human resource input. Besides, the funding input for basic research and experience research should also be increased. Furthermore, human resource input for technology transfer service is also a vital factor, which requires further introduction and training to cultivate more qualified specialists in this field.

It is shown that the $\mathrm{R} \& \mathrm{D}$ human resource input and funding input have direct correlation with patent number, and only the combination of all three regulating variables can positively regulate the correlation. The cost of research project can positively affect the relationship between funding input and patent number, which can also be explained by the reasons given before. As to the paper number, only the $\mathrm{R} \& \mathrm{D}$ funding input is correlated to it. These results demonstrate the dominant position of papers and lack of direct transfer in our country's scientific research projects. If the project number and human resource input of transfer service are both elevated, then the research outcome can be improved. When it comes to the study of real income, it is only correlated with $\mathrm{R}$ \& D human resource input, but all the regulating variables have positive effects. Besides, the input of technology popularization, including the funding input of outcome application and transfer, has no statistically significant correlation with the real income.

Several conclusions can be drawn from the results. First of all, both the overall and sub-variables should be taken into consideration during resource allocation, which requires the policies to be specified when deciding input. Secondly, the major form of technology outcome is still funding project and project cooperation, which should be expanded into more diverse forms. Thirdly, patents and papers are still the main indexes of the technology outcome performance assessment and the importance of intellectual property operation is not valued enough. Besides, R \& D human resource input has a crucial influence on the strength and quality of scientific research and should be considered as a major input. The government should pay attention to the transfer service by introduc- 
ing more service staff, providing positive environment and setting more reasonable transfer system between technologies and the market instead of just focusing on the popularization and application of the technology outcomes.

\section{Advice and Suggestion}

\subsection{More Reasonable Assessment Indexes of Agricultural Technology Outcomes}

From the analysis it is shown that the current evaluation of universities' technology outcome still focuses on the number of papers and patents and other forms of outcomes such as the application of patents and the transfer of technologies are not emphasized enough, which slows down the development of technology transfer. Therefore it is suggested that the assessing system should be broadened to include more indexes such as scientific interaction and financial income, which can lead to larger diversity of technology outcomes, better application, more reasonable resource allocation and assessment results, making scientific research become a more practical activity and offering new motivations. Besides, the feature of being practical of agricultural scientific research should be fully realized, therefore not only the financial profit but the progress created by application of new technologies should also be considered when evaluating the performance. For example, various impacts of clean production, clean food, creative culture and comprehensive agricultural entity should all be considered and they can be developed to become advantages of the industry. By this approach, further progress can be achieved in innovation and the evaluation of technology transfer can be more thorough and reasonable.

\subsection{Project Fund Management and Human Resource Recruitment}

According to the results, investing fund into various projects can lead to different outcomes, and technology outcome is directly related to all kinds of funding input including that of basic research, experience research and transfer. Besides, the market demands occupy the largest proportions in the outcome assessment system, therefore when considering which project to conduct, the actual demands should be assessed in order to provide support and resources more reasonably. Furthermore, human resource for research and transfer service has positive impacts on the transfer, therefore highly qualified scientific researchers should be recruited to enhance the quality of innovation and avoid waste of resources. Human resource of transfer service can also improve the technology outcome performance. For example, experts in this field such as technology managers can work as agents and bridge the gap between universities and enterprises to promote cooperation. On the other hand, when considering the allocation of research resources, a balance should be kept between commercial profit and public welfare. For those most fundamental or advanced research projects, the government should offer financial support, while more commercial operation should be encouraged as to those technologies which can be well applied into the industry. 


\subsection{Establish Advantageous Brand and Realize Multi-Level Production}

The evaluation of agricultural technology transfer and outcome should be more comprehensive, which means that not only the financial profits should be considered, but the effects of the technology application, the outcome quality, the long-term economic, social and environmental benefits, the attitudes of the public towards the new technologies should all be included. If the technology is applied into intelligent agriculture production, then its positive impact on environment such as less pollution and higher resource usage efficiency, and the public's acceptance should all be considered. For those technologies which are well accepted by the public, universities and governments should lay more emphasis and offer more support to them in order to promote the second level development and usage. Other relevant resources like geographic signs and intangible culture heritage should not be neglected as well and they should be combined with intelligent agriculture to realize the modernization and diversity of agricultural development from all aspects. In this process, effort should be paid to establish advantageous brands and to build unique combinations of agriculture and tourism to improve the industry's competitiveness.

\subsection{Combine Government Support and Market, Science and Public Welfare}

The transfer and application of agricultural intellectual property can affect the upgrade of the whole industry and the economic development of the rural areas, therefore the market of agricultural products has to be opened to the public with the support of the government. Apart from the transfer process, the transfer system should also be focused on, and the government should provide better protection of the intellectual properties, promote communication between the involved subjects and protect their benefits, and establish reasonable systems to allocate the profits. First of all, relevant regulations should be formulated instead of merely offering simple guidance. Secondly, the Internet can be used to build public service platform in order to strengthen the information publication and integrate resources to lower the cost and risk of the transfer. Meanwhile, the government should publish more policies to support the development of intelligent agriculture to improve the protection and create motivations. Besides, when a brand is developed to a certain extent, it should enter the competition of the market to improve its competitiveness and generate profits by itself. The benign competition between the intellectual property service organizations should also be encouraged to make the service more diverse and personalized and elevate its efficiency. With the participation of non-profit organizations, the financial and public welfare can also be balanced.

\subsection{Conduct Comprehensive Management of Intellectual Properties and Deepen the System Reform}

Since there are many types of intellectual properties and they are regulated by 
different organizations, the management is inconsistent and of low efficiency. Currently, a comprehensive management mode is being carried out as an experiment, in which the businesses about intellectual properties are managed by one department therefore to lower the cost and take advantage of the integration.

The agricultural intellectual property management also faces the same issues. The Department of Agriculture, the Industrial and Commercial Bureau and the Department of Science and Technology all have authorities over the intellectual properties, which would bring about problems. For example, the new 'Law of Seed' entitled the authority of dealing with infringement act in the seed production process to the department of agriculture and forestry and withdrew the right from the Industrial and Commercial Bureau. However, the authorities of the Industrial and Commercial Bureau include this part of right, which lead to inconsistence of the explanation of regulations. To solve this problem, the Committee of agricultural intellectual property can be established to comprehensively manage the intellectual properties and encourage social organizations and citizens to take part in the operation as a pilot run. Furthermore, an independent legislation system of agricultural intellectual property management should also be established to expand the advantages, collaborate with the agents and deepen the system reform. By these approaches, this industry can become more independent and complete, and grow into a leading role to further develop our country's agriculture and maintain the stability of our society.

The significance of this paper has two aspects, firstly, on the theoretical level, this paper combined agricultural intellectual property and intelligent agriculture together, enriching the research scope of agricultural intellectual property, also explore the endogenous mechanism, which to understand how the agricultural intellectual property influence the development of intelligent agriculture. On the practical level, this paper solved the bottle neck of agricultural intellectual property operation, and learn the developing path of intelligent agriculture, could give advice to government for making policy.

This paper also has some limitations, the mainly are as followings: first, although this paper explore the endogenous mechanism of agricultural intellectual property operation, in practice, these conclusions may not match the real circumstance, should combined investigation study jointly to open the black box of this operation mechanism. Second, although this paper studied intelligent agriculture, as the constrained of collected files, so there are not too much contents about intelligent agriculture. Thus, the study of agricultural intellectual property can be explored from these two directions, which understand the affecting mechanism deeper, and apply the research achievements into practice, connecting with the regional agriculture development.

\section{References}

[1] Sunding, D. and Zilberman, D. (2001) The Agricultural Innovation Process: Research and Technology Adoption in A Changing Agricultural Sector. Handbook of Agricultural Economics, 1,207-261.

[2] Foltz, J., Barham, B. and Kim, K. (2000) Universities and Agricultural Biotechnolo- 
gy Patent Production. Agribusiness, 16, 82-95. https://doi.org/10.1002/(SICI)1520-6297(200024)16:1<82::AID-AGR7>3.0.CO;2-V

[3] Atkinson, R.C., Beachy, R.N., Conway, G., et al. (2003) Public Sector Collaboration for Agricultural IP Management. Science, 301, 174-175.

https://doi.org/10.1126/science.1085553

[4] Wright, B.D. and Pardey, P.G. (2006) Changing Intellectual Property Regimes: Implications for Developing Country Agriculture. International Journal of Technology and Globalisation, 2, 93-114. https://doi.org/10.1504/IJTG.2006.009129

[5] Sumberg, J., Thompson, J. and Woodhouse, P. (2013) Why Agronomy in the Developing World Has Become Contentious. Agriculture and Human Values, 30, 71 83. https://doi.org/10.1007/s10460-012-9376-8

[6] Tripp, R., Louwaars, N. and Eaton, D. (2007) Plant Variety Protection in Developing Countries: A Report from the Field. Food Policy, 32, 354-371.

[7] Lalitha, N. (2004) Intellectual Property Protection for Plant Varieties: Issues in Focus. Economic and Political Weekly, 39, 1921-1927.

[8] Griliches, Z. (1958) The Demand for Fertilizer: An Economic Interpretation of a Technical Change. Journal of Farm Economics, 40, 591-606. https://doi.org/10.2307/1235370

[9] Huffman, W.E. and Evenson, R.E. (1993) The Effects of R \& D on Farm Size, Specialization, and Productivity. Industrial Policy for Agriculture in the Global Economy, 12, 41-72.

[10] Kjeldgaard, R.H. and Marsh, D. (1994) Health-Care Reform and Intellectual Property. Nature Biotechnology, 12, 639-640. https://doi.org/10.1038/nbt0694-639

[11] Powlson, D.S., Gregory, P.J., Whalley, W.R., et al. (2011) Soil Management in Relation to Sustainable Agriculture and Ecosystem Services. Food Policy, 36, S72-S87.

[12] Henle, K., Alard, D., Clitherow, J., et al. (2008) Identifying and Managing the Conflicts between Agriculture and Biodiversity Conservation in Europe-A Review. Agriculture, Ecosystems \& Environment, 124, 60-71.

Submit or recommend next manuscript to SCIRP and we will provide best service for you:

Accepting pre-submission inquiries through Email, Facebook, LinkedIn, Twitter, etc. A wide selection of journals (inclusive of 9 subjects, more than 200 journals)

Providing 24-hour high-quality service

User-friendly online submission system

Fair and swift peer-review system

Efficient typesetting and proofreading procedure

Display of the result of downloads and visits, as well as the number of cited articles

Maximum dissemination of your research work

Submit your manuscript at: http://papersubmission.scirp.org/

Or contact jssm@scirp.org 